\begin{tabular}{c}
\hline TÜRK \\
TARIM ve DOĞA BILIMLERI \\
DERGISI \\
\hline \hline
\end{tabular}

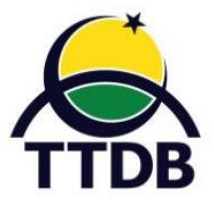

www.dergipark.gov.tr/turkjans

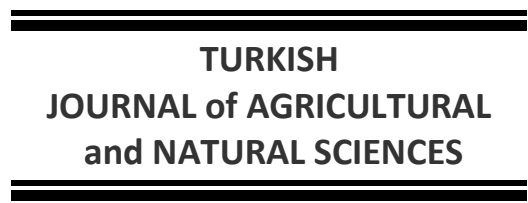

Araştırma Makalesi

\title{
In Vivo ve In Vitro Koşullarında Bazı Alkanna Taksonların Sekonder Metabolit İçerikleri ve Antioksidan Aktiviteleri
}

\author{
Cennet YAMAN ${ }^{1 *}$, Serkan URANBEY ${ }^{2}$, Muhammet ER ${ }^{3}$, Dilek BAŞALMA ${ }^{2}$ \\ ${ }^{1}$ Bozok Üniversitesi, Ziraat Fakültesi, Tarla Bitkileri Bölümü, 66900 Yozgat/Türkiye \\ ${ }^{2}$ Ankara Üniversitesi, Ziraat Fakültesi, Tarla Bitkileri Bölümü, 06100 Ankara/ Türkiye \\ ${ }^{3}$ Bozok Üniversitesi, Fen Edebiyat Fakültesi, Kimya Bölümü, 66900 Yozgat/ Türkiye \\ *Sorumlu yazar:cennet.yaman@bozok.edu.tr
}

Geliş Tarihi: 09.01.2020 Düzeltme Geliş Tarihi: 22.05.2020 Kabul Tarihi: 27.05.2020

\section{$\overline{O ̈ z}$}

Bu çalışmada in vivo koşullarda yetişmiş ve in vitro koşullarda büyütülen Alkanna orientalis (L.) Boiss. var. orientalis ve endemik Alkanna sieheana Rech. Fil. taksona ait bitki örneklerinde toplam alkanin/şikonin (A/Ş), toplam fenolik ve flavonoid içerikleri ile DPPH (2,2-difenil-1-pikrilhidrazil) aktivitelerinin belirlenmesi amaçlanmıştır. Her iki taksona ait doğadan toplanan tohumlar in vitro koşullarda farklı büyüme düzenleyicileri içeren Murashige ve Skoog (MS) besin ortamında sekonder metobolit üretimine uygun çoğaltım ve rejenerasyon ortamında kültüre alınmıştır. $A$. orientalis'de en yüksek sürgün sayısı (6.53 adet/bitki) $0.25 \mathrm{mg} \mathrm{L}^{-1}$ 6-benzil amino purin (BAP), $0.5 \mathrm{mg} \mathrm{L}^{-1}$ kinetin (KIN), $1.0 \mathrm{mg} \mathrm{L}^{-1}$ indol 3 asetik asit (IAA), A. sieheana'da ise 5.57 adet/bitki ile $0.25 \mathrm{mg} \mathrm{L}^{-1}$ BAP, $0.5 \mathrm{mg} \mathrm{L}^{-1} \mathrm{KIN}, 1.0 \mathrm{mg} \mathrm{L}^{-1}$ indol 3 butirik asit. (IBA) içeren besin ortamında elde edilmiştir. Her iki taksonda en yüksek ekstrakt verimi in vivo dan toplanan örneklerde saptanmıştır. A. orientalis taksonunda en yüksek toplam fenolik içerik $172.80 \mathrm{mg}$ gallik asit eşdeğer (GAE) $\mathrm{g}^{-1}$ ekstrakt ile in vivo koşullarında kök ekstraktında, A. sieheana için ise $122.99 \mathrm{mg} \mathrm{GAE} \mathrm{g}^{-1}$ ekstrakt ile in vivo koşullarda herba ekstraktında gözlenmiştir. Her iki takson için de en yüksek toplam flavonoid içerik yine in vivo koşularındaki ekstraklarda belirlenmiştir. A. sieheana türünde en yüksek toplam A/Ş içeriği (61.45 $\mu \mathrm{g} \mathrm{g}^{-1}$ ekstrakt) in vivo koşullarındaki köklerinden elde edilmiş ve $A$. orientalis köklerinden 23 kat daha fazla olduğu saptanmıştır. En yüksek radikal kovucu aktivite ise $A$. orientalis için $1000 \mu \mathrm{g} \mathrm{m}^{-1}$ konsantrasyonda in vivo koşullarında köklerden, A. sieheana için $1500 \mu \mathrm{g} \mathrm{ml}^{-1}$ konsantrasyonda yine in vivo koşularındaki herba kısmında belirlenmiştir.

Anahtar Kelimeler: Alkanna, Alkanin/Şikonin, DPPH, Fenolik, Flavonoid

\section{Secondary Metabolite Contents and Antıoxidant Activities of Some Alkanna Taxa Under In Vivo And In Vitro Conditions}

\begin{abstract}
Absract
The goal of this study was to investigate total phenolic and flavonoid contents, total Alkannin/Shikonin (A/S) and DPPH (2,2-diphenyl-1-pikrilhidrazil) activity of plant samples of A. orientalis and endemic Alkanna sieheana under in vitro and in vivo conditions. The seeds of both species were cultured on MS medium containing different growth regulators under in vitro conditions for suitable metabolite production. The highest number of shoot (6.53 number/plant) in $A$. orientalis on was obtained on MS medium containing $0.25 \mathrm{mg} \mathrm{L}^{-1} 6$ benzyl amino purin (BAP), $0.5 \mathrm{mg} \mathrm{L}^{-1}$ kinetin (KIN), $1.0 \mathrm{mg} \mathrm{L}^{-1}$ indole 3 acetic acid (IAA) and 5.57 number/plant in A. sieheana on $0.25 \mathrm{mg} \mathrm{L}^{-1} \mathrm{BAP}, 0.5 \mathrm{mg} \mathrm{L}^{-1} \mathrm{KIN}$ and1.0 $\mathrm{mg} \mathrm{L}^{-1}$ indole 3 butyric acid. (IBA). The highest extract yields were determined on samples obtained from in vivo conditions. The highest total phenolic content was observed the root extract in vivo with $172.80 \mathrm{mg}$ gallic acid equivalent (GAE) $\mathrm{g}^{-1}$ extract for $A$. orientalis, and shoot extract in vitro with $122.99 \mathrm{mg} \mathrm{GAE} \mathrm{g}^{-1}$ extract for $A$. sieheana. The highest total flavonoid content was determined from obtained from in vivo conditions. The highest total A/S content with $61.45 \mu \mathrm{g} \mathrm{g}^{-1}$ ekstrakt was obtained from roots of $A$. sieheana and found about 23 times higher than content in root of $A$. orientalis from in vivo conditions The highest radical scavening activity was determined under in vivo conditions from root at
\end{abstract}


$1500 \mu \mathrm{g} \mathrm{ml} l^{-1}$ concentration for $A$. orientalis and from shoot in vivo at $1500 \mu \mathrm{g} \mathrm{ml} \mathrm{l}^{-1}$ concentration for $A$. sieheana.

Keywords: Alkanna, Alkannin/Shikonin, DPPH, Fenolic, Flavonoid

\section{Giriş}

Alkanna cinsi Boraginaceae (Hodangiller) familyasına ait otsu yapıda ve dünyada yaklaşık 50 tür ile temsil edilmektedir (Mahmoudi ve ark., 2012). Türkiye florasında 36 tür ve 32 'si endemik 41 takson ile yaklaşık \%80 endemizm oranı sahip önemli bir cindir (Davis ve ark., 1988; Güner ve ark., 2012). Alkanna cinsi, 1500 m yükseklikte yayılış gösteren yarı çalımsı formda ve NisanAğustos aylarında çiçeklenen çok yıllık türlere sahiptir. Çiçek renkleri sarı, mavi, beyaz tonlarında ve hoş kokuludur. Yaprakları tüylüdür. (Davis ve ark., 1988). Alkanna cinsi genel olarak ülkemizde havacivaotu olarak bilinmesine rağmen taksonları ülkemizde değişik yöresel isimlerle tanınmaktadır. A. orientalis (L.) Boiss. var. orientalis sarı çiçekli ve sarı somuk olarak bilinen yaygın bir taksondur. $A$. sieheana Rech. fil. türü ise mavi çiçekli olup, yerineği ismi ile bilinen endemik bir türdür (Güner ve ark., 2012).

Her iki tür de köklerinde ticari önemi olan enantiyomerik izohekzenilnaftazarin (Alkanin/Şikonin (A/Ş) ve türevleri) renk pigmentleri içermektedirler (Assimopoulou ve ark., 2006). Uzun yıllardır A/ş ve türevleri tekstil, gıda, kozmetik gibi alanlarda boyama amaçlı kullanılmaktadır. Tıp ve farmakoloji alanlarında güçlü bir yara iyileştirici (Papageorgiou ve ark., 2008), antimikrobial (Haghbeen ve ark., 2011), anti inflamatuar (Mahmoudi ve ark., 2012), antitrombotik, sitotoksik (Gür ve ark., 2010), antioksidant (Assimopoulou ve Papageorgiou, 2005), enzim inhibitörü (Kajimoto ve ark., 2008) gibi çeşitli biyolojik aktivitelere sahip olduğu tespit edilmiştir. En son araştırmalarda da anti tümor özelliği olduğu ortaya konmuştur (Han ve ark., 2019; Xu ve ark., 2019).

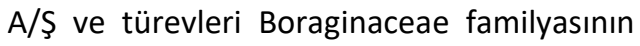
Alkanna, Onosma, Arnebia, Lithospermum ve Echium cinslerine ait yaklaşık 150 türünün köklerinde doğal olarak bulunduğu bilinmektedir (Kumar ve ark., 2011). Köklerinde A/ş bulunduran cinslere ait türler genellikle doğada yabani formları bulunan kültüre henüz alınmamış doğal bitkilerdir. Ayrıca birçoğunun köklerindeki $\mathrm{A} / \mathrm{s}$ miktarları ile ilgili literatür hemen hemen bulunmamaktadır. Bazı türlerin çok yıllık olması ve optimum ticari $A / S ̧$ üretiminin 6-7 yıl sonra köklerde birikmesi (Hunter ve Kilby 1990) gibi sebeplerden dolayı kültüre alınarak bileşiklerin ticari üretimini zorlaştırmaktadır. Ayrıca, farklı lokalite ve ortamlardan toplandığı için ticari anlamda anlamlı ve stabil bir madde temini elde edilmemektedir. Bilindiği üzere bitki doku kültürü teknikleri ile sekonder metabolit üretimini teşvik edilebilmektedir. Farklı bitki kısımları kullanılarak, kültür koşulları, besin ortamları, elisitörler ve diğer abiyotik ve biyotik stres faktörleri modifiye edilerek daha fazla, daha kısa sürede, daha steril ve stabil sekonder metabolit üretimi yapılabilmektedir. Ayrıca in vitro ve in vivo koşullarda sekonder metobolit üretimi ve antioksidan içeriğinde değişimler meydana gelebilmektedir (Tošić ve ark., 2019). Bu çalışmada da $A$. orientalis ve $A$. sieheana taksonların in vitro ve in vivo örneklerinde ekonomik önemi yüksek olan $A / S ̧$ içerikleri ve antioksidan aktiviteleri incelenmiştir.

\section{Materyal ve Yöntem Materyal}

Alkanna sieheana Rech. fil. taksonu (endemik) Konyanın Çumra ilçesi Apasaraycık köyünden 1090 m'den ve Alkanna orientalis (L.) Boiss var. orientalis taksonu ise Yozgat Bozok Üniversitesi Kampüsü 1399 m’den toplanmıştır. Tür teşhisi Selçuk Üniversitesi, Eczacılık Fakültesi Öğretim Üyesi Prof. Dr. Osman TUGAY tarafından yapılmıştır. Taksonların tohumları ve bitki örnekleri 2015 yılında $A$. sieheana taksonu Mayıs ayında, $A$. orientalis türü ise Haziran ayında doğadan toplanmıştır. Bitkiler Selçuk Üniversitesi, Fen Fakültesi, KNYA herbaryumda $A$. sieheana ve $A$. orientalis, sırasıyla 26.095 ve 26.088 herbaryum numarası ile numaralandırılmış ve toplama yerleri kaydedilmiştir.

\section{In vitro tohumların yüzey sterlizasyonu çoğaltımı}

Denemede her iki türe ait koyu kahve renkli (olgun) tohumlar kullanılmıştır. Her iki taksonun tohumları da \%20 NaOCl'de 20 dk bekletilerek, tohumların yüzey sterilizasyonu yapılmıştır. Sterilizasyon sonrası tohumlar steril saf su ile 3-4 kez durulanmış, son durulamada tohumlar steril saf su da 1 saat bekletilmiştir. In vitro çalışmalarda kullanılan temel besin ortamları $121{ }^{\circ} \mathrm{C}$ 'de ve 1.2 atm basınçta $20 \mathrm{dk}$ steril edilmiştir.

in vitro çalışmalarda taksonlarının olgunlaşmış tohumlarının tohum kabukları çıkartılarak elde edilen sürgünler $0.25 \mathrm{mg} \mathrm{L}^{-1} \mathrm{BAP}, 0.5 \mathrm{mg} \mathrm{L}^{-1} \mathrm{KIN}$, $1.0 \mathrm{mg} \mathrm{L}^{-1}$ IAA içeren ortamda 15 günde bir alt kültüre alınmış ve gelişen sürgünler eksplant kaynağı olarak kullanılmıştır (Şekil 1). Eksplant 
kaynağı olarak tercih edilen sürgünlerin yaşların 4 haftalık ve 4-5 yapraklı olmasına dikkat edilmiştir. Elde edilen sürgünlerden Şekil 1B'de gösterildiği gibi sürgün eksplantları farklı dozlarda büyüme düzenleyicileri içeren MS besin ortamında $24 \pm 1{ }^{\circ} \mathrm{C}$ de ve 16000 lüks altında 16/8 saat ışıklandırma koşullarında kültüre alınmıştır. Kültürden 30 gün sonra elde edilen örneklerde ekstrakt hazırlanmıştır.

\section{Ekstraktların hazırlanması}

In vivo ortamdan toplanan bitki örneklerinin toprak üstü ve kök kısımları gölgede kurutulmuş ve sonra kesilerek öğütülmüştür. In vitro şartlarda elde edilen sürgünler ise sıvı azot ile toz haline getirilmiştir. Ekstraksiyon işleminde $5 \mathrm{~g}$ örnek üzerine $50 \mathrm{ml}$ metanol eklenmiştir. Her örnek için uygulamalar 3 tekrarlı olarak yapılmıştır. Örnekler etüvde $40{ }^{\circ} \mathrm{C}^{\prime}$ de 24 saat bekletilmiştir. Elde edilen çözeltiler santrifüj cihazında toprak üstü ve kök çözeltileri 4.500 rpm'de santrifüj edilmiştir. Doku kültüründan alınan örnekler ise 9.000 rpm'de santrifüj edilmiştir. Süpernat kısımları alınmış ve evaporatör yardımı ile organik çözücü uzaklaştırılmış, ekstrakt verimi \% (w/w) olarak elde edilmiştir. Antioksidan çalışmaları için ekstraktlar +4 ${ }^{\circ} C^{\prime}$ de muhafaza edilmiştir. A/Ş analizi için elde edilen ekstraktlar $0.22 \mu \mathrm{m}$ delik çapına sahip filtreden geçirilmiş, $-20^{\circ} \mathrm{C}^{\prime}$ de bekletilmiştir.

\section{Toplam fenolik içeriğin belirlenmesi (folin yöntemi)}

Ekstraktların toplam fenolik içeriği FolinCiocalteu Reaktifi (FCR) ile Singleton ve ark. (1999) metodu modifiye edilerek yapılmıştır. Analizde (2 $\mathrm{mg} / \mathrm{ml}$ ) örnek çözeltilerinden $0.2 \mathrm{ml}$ alınmış ve üzerine $9 \mathrm{ml}$ distile su ilave edildikten sonra $0.2 \mathrm{ml}$ Folin-Ciocalteu ve $0.6 \mathrm{ml} \mathrm{Na} \mathrm{CO}_{3}$ (\%20) eklenmiş ve toplam hacim $10 \mathrm{ml}$ olacak şekilde ayarlanmıştır. Oda sıcaklığında 2 saat karanlıkta inkübe ettikten sonra, $760 \mathrm{~nm}$ 'de absorbans ölçümü yapılmıştır. Standart kalibrasyon eğrisi oluşturmada gallik asit kullanılmıştır. Gallik asit standart grafiğine göre tüm bitki ekstraktlardaki toplam fenolik madde mg gallik asit eşdeğeri (GAE) $\mathrm{g}^{-1}$ ekstrakt olarak hesaplanmıştır ( $\left.y=0,0098 x+0,0253 ; R^{2}=0,9989\right)$. Her bir deneme 4 tekerrürlü olarak yapılmıştır.

\section{Toplam flavonoid içeriğin belirlenmesi}

Ekstraktların toplam flavonoid içeriği Arvouet-Grand ve ark. (1994) yöntemine göre saptanmıştır. Deneyde \%10'luk alüminyum nitrattan $100 \mu \mathrm{l}, 1 \mathrm{M}$ potasyum asetattan $100 \mu \mathrm{l}$ alınıp, bitki ekstraktının son konsantrasyonu $100 \mu \mathrm{g}$ $\mathrm{ml}^{-1}$ olacak şekilde ekstrakt ilave edilmiştir. Deney etanol ile 5 ml'ye tamamlanmıştır. Oda sıcaklığında $40 \mathrm{dk}$ karanlıkta inkübe ettikten sonra $417 \mathrm{~nm}$ 'de absorbans ölçümü yapılmıştır. Standart kalibrasyon eğrisi oluşturmada kuersetin kullanılmıştır. Toplam flavonoid madde içeriği mg kuarsetin eşdeğeri (KE) $\mathrm{g}^{-1}$ ekstrakt olarak ifade edilmiştir $\left(y=0,0055 x+0,0063 ; R^{2}=0,9995\right)$. Her bir deneme 4 tekerrürlü olarak yapılmıştır.

\section{Toplam alkanin/şikonin tayini}

Ekstrakların toplam A/ş miktarı LC-20A model (Shimadzu, Japan) Yüksek Performanslı Sıvı Kromatografisi (HPLC) cihazı tarafından yapılmıştır. Kolon olarak Inertsil $\mathrm{C}_{18}$ ODS-3 (5 $\mu \mathrm{m}, 4.6 \mathrm{~mm} \times 250$ $\mathrm{mm}$, Japan) kolonu kullanılmıştır. Hareketli faz organik düzenleyici $\% 90$ asetonitril ile $\% 10$ su ve hareketli fazın akış hızı $0.80 \mathrm{ml} / \mathrm{dk}$ olarak ayarlanmıştır. SPD-M20A photodiode array (PDA) detektörü (Shimadzu, Japan) ile 520 nm'de absorbans ölçümü yapılmıştır. Miktar tayini standart olarak kullanılan alkanin maddesinin kalibrasyon denklemi kullanılarak hesaplanmıştır (Assimopoulou ve ark., 2006). Alkanin miktarı $\mathrm{R}^{2}=$ 0,9964 olan $y=139385 x+8384,9$ denklemine göre hesaplanmıştır (Rt:5.28).

\section{Radikal kovucu aktivitesi}

Ekstraktların serbest radikal kovucu aktiviteleri bilinen bir radikal olan DPPH (2,2difenil-1-pikrilhidrazil) serbest radikali kullanılarak belirlenmiştir (Gezer ve ark., 2006). DPPH radikali süpürücü aktivite tayini için $4 \mathrm{mg}$ DPPH, $100 \mathrm{ml}$ metanol içerisinde çözülmüştür. Örneklerden ana stok olarak $2 \mathrm{mg} / \mathrm{ml}$ ekstrakt çözeltisi hazırlanmış ve bu stoktan farklı konsantrasyonlarda $(250,500$, 750, 1000, 1500, $2000 \mu \mathrm{g} / \mathrm{ml}$ ) seyreltmeler hazırlanmıştır. Her bir örnek için $3.2 \mathrm{ml} \mathrm{DPPH}$ radikali ve farklı konsantrasyonlardaki ekstrakt çözeltilerinden $200 \mu \mathrm{l}$ ilave edilmiştir. Oda sıcaklığında $30 \mathrm{dk}$ karanlıkta inkübe ettikten sonra 517 nm'de absorbans ölçümü yapılmıştır. Standart antioksidan olarak askorbik asit ve bütillenmiş hidroksi toluen (BHT) kullanılmıştır. Kontrol için deney tüpüne ekstrakt çözelti miktarı kadar metanol ilave edilmiştir. Her bir deneme 3 tekerrürlü olarak yapılmış, her tekerrür iki tekrarlı olarak yapılmıştır. Örneklerin DPPH radikal kovucu aktivitesi \% olarak aşağıdaki formüle göre hesaplanmıştır.

$\%$ DPPH radikal kovucu aktivitesi $=\left[\left(A_{\text {kontrol }}-\right.\right.$ Aekstrakt)/A kontrol] x 100

\section{Verilerin istatistiksel değerlendirilmesi}

Veriler Düzgüneş vd. (1983) tarafından bildirildiği şekilde varyans analizi yapılmış ve ortalamar arasındaki fark Duncan çoklu karşılaştırma testi ile kıyaslanmıştır. Her bir örneğin standart hataları ortalama değerlerinin yanında \pm ile verilmiştir. 
Bulgular ve Tartışma

\section{In vitro çoğaltım ve sürgün rejenerasyonu}

Farklı besin ortamlarında kültüre alınan $A$. orientalis türünde en yüksek sürgün sayısına (6.53 adet/bitki ) ve sürgün boyuna $(5.37 \mathrm{~cm}) 0.25 \mathrm{mg} \mathrm{l}^{-1}$ $\mathrm{BAP}, 0.5 \mathrm{mg} \mathrm{l}^{-1} \mathrm{KIN}, 1.0 \mathrm{mg} \mathrm{l}^{-1} \mathrm{IAA}$ içeren MS besin ortamında saptanmıştır. A. sieheana türünde ise en yüksek sürgün sayısına (5.57 adet/bitki) ve sürgün boyuna $(5.37 \mathrm{~cm}) 0.25 \mathrm{mg} \mathrm{l}^{-1} \mathrm{BAP}, 0.5 \mathrm{mg} \mathrm{l}^{-1}$ $\mathrm{KIN}, 1.0 \mathrm{mg} \mathrm{l}^{-1}$ IBA içeren $\mathrm{MS}$ besin ortamında bulunmuştur (Çizelge 1 ).
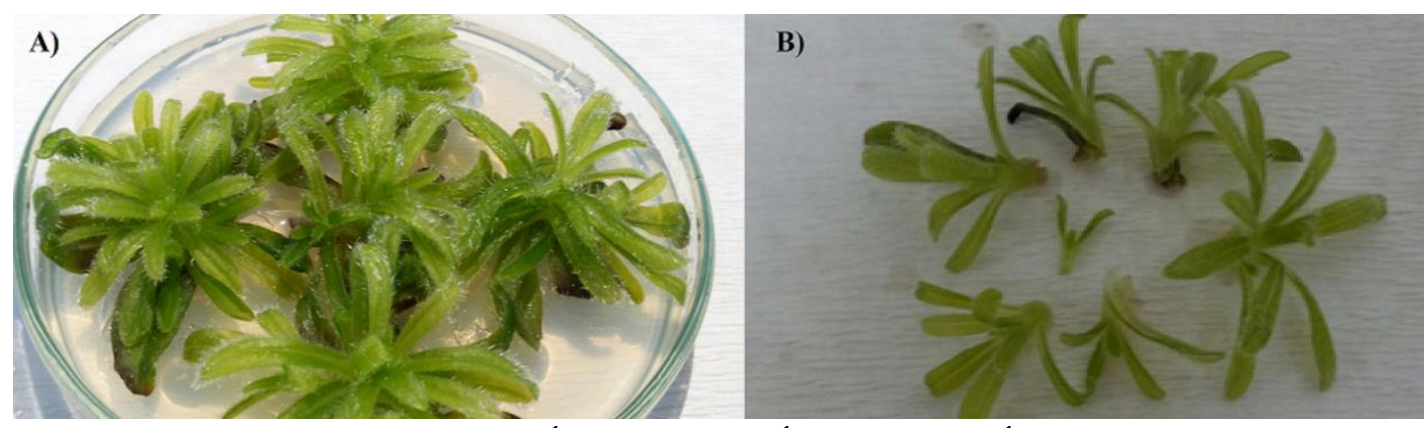

Şekil 1. A. orientalis sürgünlerin $0.25 \mathrm{mg} \mathrm{L}^{-1} \mathrm{BAP}, 0.5 \mathrm{mg} \mathrm{L}^{-1} \mathrm{KIN}, 1.0 \mathrm{mg} \mathrm{L}^{-1}$ IAA ortamında: A) 30 gün sonraki görüntüsü, B) 30 günlük bitkilerden elde edilen tek sürgünler (eksplant kaynağı).

Çizelge 1. A. orientalis ve $A$. sieheana taksonlarının farklı büyüme düzenleyici uygulamalarının in vitro şartlarda sürgün sayısı ve sürgün boyuna etkisi

\begin{tabular}{cccccccc}
\hline \multicolumn{2}{c}{ Büyüme Düzenleyicileri (mg/L) } & \multicolumn{2}{c}{ A. orientalis } & \multicolumn{2}{c}{ A. sieheana } \\
\hline KIN & BAP & IBA & IAA & $\begin{array}{c}\text { Sürgün sayısI } \\
\text { (adet) }\end{array}$ & $\begin{array}{c}\text { Sürgün boyu } \\
\text { (cm) }\end{array}$ & $\begin{array}{c}\text { Sürgün sayısı } \\
\text { (adet) }\end{array}$ & $\begin{array}{c}\text { Sürgün boyu } \\
\text { (cm) }\end{array}$ \\
\hline 0.5 & 0.25 & - & 1.0 & $6.53 \pm 0.82$ & $5.37 \pm 0.06 \mathrm{a}$ & $4.67 \pm 0.53$ & $4.97 \pm 0.12 \mathrm{a}$ \\
0.5 & 0.25 & 1.0 & - & $4.50 \pm 0.17$ & $4.10 \pm 0.11 \mathrm{~b}$ & $5.57 \pm 0.12$ & $5.37 \pm 0.06 \mathrm{a}$ \\
- & - & 2.0 & - & $5.20 \pm 0.23$ & $5.00 \pm 0.34 \mathrm{a}$ & $4.67 \pm 0.14$ & $4.40 \pm 0.09 \mathrm{~b}$ \\
\hline
\end{tabular}

Aynı sütundaki küçük harflerle gösterilen ortalamalar arasındaki fark 0.01 düzeyinde önemlidir.

Sürgün oluşumunda her iki tür içinde en etkili ortamın $0.25 \mathrm{mg} \mathrm{l}^{-1} \mathrm{BAP}, 0.5 \mathrm{mg} \mathrm{l}^{-1} \mathrm{KIN}, 1.0 \mathrm{mg}$ $\mathrm{I}^{-1}$ IAA içeren $\mathrm{MS}$ besin ortamının uygun olduğu görülmüştür. Benzer şekilde, Pal ve Chaudhury (2010) çalışmalarında Boraginacaea familyasına ait ve köklerinde $A / S ̧$ içeren Arnebia hispidissima türünün $B A P, K I N$, IAA içeren ortamlarda sürgün gelişiminin daha iyi olduğu bildirilmiştir.

\section{Ekstraksiyon verimi}

Çizelge 2 incelendiğinde, örneklerin ekstrakt verimleri \%9.3 ile 1.1 arasında değişmiştir. $A$. orientalis ve $A$. sieheana en yüksek ekstrakt verimi, her iki taksonda da bitkinin herba kısmından (sırasıyla \%9.3, \%5.5) elde edilmiştir. Özer ve ark.
(2010) Alkanna tinctoria türünün kuru herbal kısımlarından metanollü ekstrakt verimini \%5.29 rapor etmiştir. En düşük ekstrakt verimi ise yine her iki taksonda da $0.25 \mathrm{mg} \mathrm{l}^{-1} \mathrm{BAP}, 0.5 \mathrm{mg} \mathrm{l}^{-1} \mathrm{KIN}$, $1.0 \mathrm{mg} \mathrm{l}^{-1}$ IBA içeren sürgün örneklerinde (sırasıyla \%1.1, \%1.6) tespit edilmiştir. Chang ve ark. (2008) Arnebia euchroma ve Lithospermum erythrorhizon türlerinin köklerinin metanollü ekstrakt verimlerini sırasıyla \%7.21 ve \%6.58 olarak bulmuşlardır. $A$. orientalis ve $A$. sieheana taksonlarının kök ekstrakt verimi sırayla \%3.7 ve \%5.3 olarak kaydedilmiştir. Her iki taksonun in vitro örneklerin ekstrakt verimleri in vivo örneklerinden daha düşük olduğu tespit edilmiştir.

Çizelge 2. A. orientalis ve $A$. sieheana taksonlarının in vivo ve in vitro örneklerinin ekstrakt verimi

\begin{tabular}{|c|c|c|c|c|c|c|c|c|c|}
\hline \multirow[t]{3}{*}{ No } & \multirow{3}{*}{ Eksplant } & \multicolumn{5}{|c|}{ Büyüme düzenleyiciler $\left(\mathrm{mg} \mathrm{L}^{-1}\right)$} & \multirow{3}{*}{ Ekstrakt örneği } & \multirow{2}{*}{\multicolumn{2}{|c|}{$\begin{array}{c}\text { Elde edilen } \\
\text { ekstrakt yüzdesi } \\
(\%)\end{array}$}} \\
\hline & & \multirow[t]{2}{*}{ BAP } & \multirow[t]{2}{*}{ KIN } & \multirow[t]{2}{*}{ NAA } & \multirow[t]{2}{*}{ IAA } & \multirow[t]{2}{*}{ IBA } & & & \\
\hline & & & & & & & & A.O & A.S \\
\hline 1 & Sürgün & 0.25 & 0.5 & - & 1.0 & - & Sürgün & 2.8 & 2.2 \\
\hline 2 & Sürgün & 0.25 & 0.5 & - & - & 1.0 & Sürgün & 1.1 & 1.6 \\
\hline 3 & Sürgün & - & - & - & - & 2.0 & Tam Bitki & 2.6 & 3.7 \\
\hline 4 & & & vo ort & ndaki & & & Herba & 9.3 & 5.5 \\
\hline 5 & & & vo ort & ndaki & & & Kök & 3.7 & 5.3 \\
\hline
\end{tabular}

${ }^{*}$ A.O: A. orientalis var. orientalis, A.S: A.sieheana Rech. fil. 


\section{Toplam fenolik içerik}

A. orientalis taksonuna ait örneklerde toplam fenolik değerleri 5.08-172.80 $\mathrm{mg}_{\mathrm{GAE}} \mathrm{g}^{-1}$ ekstrakt arasında, $A$. sieheana taksonunda ise 5.11122.99 mg GAE g ${ }^{-1}$ ekstrakt arasında değiştiği gözlenmiştir (Çizelge 3). En yüksek toplam fenolik içeriğin $172.80 \mathrm{mg} \mathrm{GAE} \mathrm{g}^{-1}$ ekstrakt ile $A$. orientalis taksonunun kök ekstrakından elde edilmiştir. $A$. sieheana taksonunda ise $122.99 \mathrm{mg} \mathrm{GAE} \mathrm{g}^{-1}$ ekstrakt ile gövde ekstraktında tespit edilmiştir. Her iki taksonun in vitro örnekleri in vivo örneklerinden daha düşük toplam fenolik içeriğe sahip olduğu gözlenmiştir.

Boraginaceae familyasının köklerinde $\mathrm{A} / \mathrm{S}$ içeren türleri incelendiğinde, Alkanna tinctoria türünün herba kısmının toplam fenolik miktarını Şengül ve ark. (2009) 11.57 mg GAE g ${ }^{-1}$ kuru ağırlık,

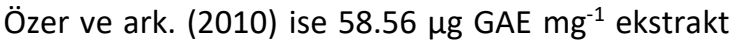
bulmuşlardır. Fakat $A$. orientalis ve $A$. sieheana taksonlarının herba (sırasıyla 102.66 ve 122.99 mg GAE $g^{-1}$ ekstrakt) kısımlarında daha yüksek toplam fenolik içerik tespit edilmiştir. Chang ve ark. (2008) Arnebia euchroma ve Lithospermum erythrorhizon türlerinin köklerindeki toplam fenolik içeriklerini sırasıyla 150.70 ve 138.60 mg KE g ${ }^{-1}$ ekstrakt olarak kaydetmişlerdir. $\mathrm{Bu}$ değerlerin $A$. orientalis köklerinkindeki toplam fenolik içeriğinden düşük, A. sieheana taksonunkinden ise yüksek olduğu saptanmıştır.

Çizelge 3. A. orientalis ve $A$. sieheana taksonuna ait örneklerin toplam fenolik, toplam flavonoid ve $A / S ̧$ içerikleri

\begin{tabular}{|c|c|c|c|c|c|c|c|c|c|c|c|c|c|}
\hline \multirow{3}{*}{ No } & \multirow{3}{*}{ Eksplant } & \multicolumn{5}{|c|}{ Büyüme düzenleyiciler $\left(\mathrm{mg} \mathrm{L}^{-1}\right)$} & \multirow{3}{*}{$\begin{array}{l}\text { Ekstrakt } \\
\text { örneği }\end{array}$} & \multirow{2}{*}{\multicolumn{2}{|c|}{$\begin{array}{l}\text { Toplam fenolik } \\
\text { içerik } \\
\text { ( mg GAE g } \\
\text { ekstrakt) }\end{array}$}} & \multirow{2}{*}{\multicolumn{2}{|c|}{$\begin{array}{c}\text { Toplam } \\
\text { flavonoid içerik } \\
\text { ( } \mathrm{mg} \mathrm{KE} \mathrm{g}^{-1} \\
\text { ekstrakt) }\end{array}$}} & \multirow{2}{*}{\multicolumn{2}{|c|}{$\begin{array}{c}\text { Alkanin/Şikonin } \\
\text { miktarı } \\
\text { ( } \mathrm{g} \mathrm{g}^{-1} \text { ekstrakt) }\end{array}$}} \\
\hline & & \multirow[t]{2}{*}{ BAP } & \multirow[t]{2}{*}{ KIN } & \multirow[t]{2}{*}{ NAA } & \multirow[t]{2}{*}{ IAA } & \multirow[t]{2}{*}{ IBA } & & & & & & & \\
\hline & & & & & & & & A.O & A.S & A.O & A.S & A.O & A.S \\
\hline 1 & Sürgün & 0.25 & 0.5 & - & 1.0 & - & Sürgün & 75.32 & 109.61 & 138.44 & 2.32 & nd & 14.678 \\
\hline 2 & Sürgün & 0.25 & 0.5 & - & - & 1.0 & Sürgün & 123.58 & 110.56 & 95.62 & 139.89 & nd & nd \\
\hline 3 & Sürgün & - & - & - & - & 2.0 & $\begin{array}{l}\text { Tam } \\
\text { Bitki }\end{array}$ & 49.15 & 20.65 & 9.07 & 7.38 & nd & nd \\
\hline 4 & & & vo ort & mdaki & & & Herba & 102.66 & 122.99 & 67.31 & 10.22 & nd & nd \\
\hline 5 & & & vo ort & mdaki & & & Kök & 172.80 & 93.48 & 22.07 & 11.44 & 2.705 & 61.457 \\
\hline
\end{tabular}

${ }^{*}$ A.O: A. orientalis var. orientalis, A.S: A.sieheana Rech. fil. ${ }^{*}$ nd, belirlenemedi

\section{Toplam flavonoid içerik}

Toplam flavonoid değerleri $A$. orientalis taksonuna ait örneklerde 9.07-138.44 $\mathrm{mg} \mathrm{KE} \mathrm{g^{-1 }}$ ekstrakt arasında değişirken, $A$. sieheana

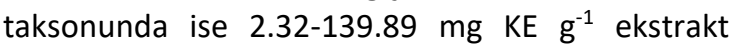
arasında değiştiği gözlenmiştir. Çizelge 3 incelendiğinde, her iki taksonun in vitro uygulamalarından elde edilen bazı örneklerindeki toplam flavonoid içeriklerinin in vivo kök ve herba kısımlarından daha yüksek bulunmuştur. En yüksek toplam flavonoid içerik $A$. orientalis için $138.44 \mathrm{mg}$ $\mathrm{KE} \mathrm{g}^{-1}$ ekstrakt ile $0.25 \mathrm{mg} \mathrm{l}^{-1} \mathrm{BAP}, 0.5 \mathrm{mg} \mathrm{l}^{-1} \mathrm{KIN}, 1.0$ $\mathrm{mg} \mathrm{I}^{-1} \quad$ IAA ortamından elde edilen sürgün örneklerinde, $A$. siehena için ise $139.89 \mathrm{mg} \mathrm{KE} \mathrm{g}^{-1}$ ekstrakt ile $0.25 \mathrm{mg} \mathrm{l}^{-1} \mathrm{BAP}, 0.5 \mathrm{mg} \mathrm{l}^{-1} \mathrm{KIN}, 1.0 \mathrm{mg} \mathrm{l}^{-1}$ IBA ortamından elde edilen sürgün örneklerinde tespit edilmiştir. $A$. orientalis ve $A$. sieheana taksonlarının toplam flavonoid içerikleri için büyüme düzenleyicilerinin pozitif etki yapabileceği tespit edilmiştir. Hatta toplam fenolik içerikten daha yüksek olduğu gözlenmiştir. Benzer olarak Vinothini ve ark. (2017) çalışmalarında bazı in vitro örneklerinden elde ettikleri toplam flavonoid içeriklerin toplam fenolik içeriğinden yüksek olduğunu rapor etmiştir.

\section{Toplam alkanin/şikonin (A/ş) tayini}

$A$. orientalis ve $A$. sieheana taksonlarının in vivo ve in vitro örneklerinin toplam $A / S ̧$ miktarı alkanin standart kalibrasyon eğrisine göre $\mu \mathrm{g} / \mathrm{g}$ ekstrakt cinsinden hesaplanmış ve sonuçlar çizelge $3^{\prime}$ de verilmiştir. Sonuçlara göre $A$. sieheana taksonunun doğal ortamdaki köklerinden (61.457

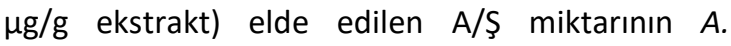
orientalis taksonunun doğal ortamdan elde edilen köklerindekinden $(2.705 \mu \mathrm{g} / \mathrm{g}$ ekstrakt) yaklaşık olarak 23 kat daha yüksek olduğu tespit edilmiştir. Ayrıca $A$. sieheana bitkisinin in vitro şartlarda 0.5 $\mathrm{mg} \mathrm{L}^{-1} \mathrm{KIN}, 0.25 \mathrm{mg} \mathrm{L}^{-1} \mathrm{BAP}, 1.0 \mathrm{mg} \mathrm{L}^{-1} \mathrm{IAA}$ ortamından elde edilen sürgün örneklerinde $A / S$ miktarı $14.678 \mu \mathrm{g} / \mathrm{g}$ ekstrakt olarak bulunmuş ve $A$. orientalis taksonunun doğal ortamındaki köklerinden yaklaşık 6 kat daha yüksek olduğu gözlenmiştir. Sonuçlara göre, $A$. sieheana taksonunun $A / S ̧$ üretiminde önemli bir takson olduğunu düşündürmektedir. Köklerinde $A$ /Ş içeren türler üzerinde yapılan çalışmalarda, IAA büyüme düzenleyici destekli besin ortamlarında fazla hücre artış olduğu (Bageri ve ark., 2011), fakat karanlık şartlarda ise alkanin miktarında artış olduğu bildirilmiştir (Haghbeen ve ark., 2011). BAP ve IAA içeren besin ortamlarında da kallus gelişiminin ve 
A/Ş miktarının arttığını rapor edilmiştir (Chung ve ark., 2006; Zare ve ark., 2010).

\section{DPPH radikal kovucu aktivite}

$A$. orientalis ve $A$. sieheana taksonlarının in vivo ve in vitro örneklerinin $250,500,750,1000$, 1500 ve $2000 \mu \mathrm{g} \mathrm{ml}^{-1}$ konsantrasyonlarındaki DPPH aktiviteleri incelenmiş ve \% inhibisyon değerleri Şekil 3 - 4'de gösterildiği gibi hesaplanmıştır. Standart antioksidan olarak bilinen askorbik asit'in DPPH radikal kovucu aktivitesi Şekil 2'de verilmiştir. Askorbik asit standartının DPPH aktivitelerinin her iki taksonun örneklerine göre yüksek olduğu gözlenmiştir.

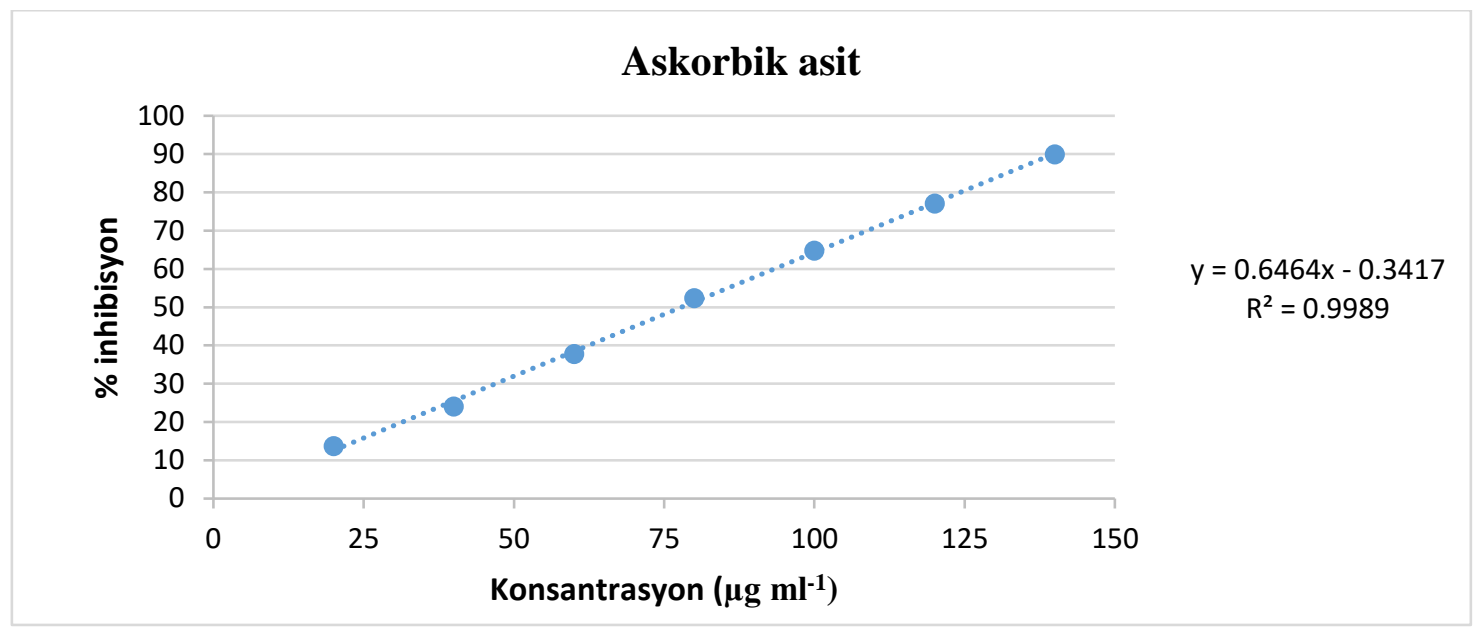

Şekil 2. Askorbik asit standartının farklı konsantrasyonlarda DPPH aktivitesi

Şekil 3 incelendiğinde, $A$. orientalis taksonunun örnekleri arasında her bir konsantrasyonda en yüksek DPPH aktivitesinde kök örneği sahip olduğu ve herba örneğinin in vitro örneklerinden daha düşük aktivite sergilediği kaydedilmiştir. A. siehena taksonunda ise her bir konsantrasyonda en yüksek aktivite herba örneğinde gözlenmiş ve kök örneğinin $0.5 \mathrm{mg} \mathrm{L}^{-1}$ $\mathrm{KIN}, 0.25 \mathrm{mg} \mathrm{L}^{-1} \mathrm{BAP}, 1.0 \mathrm{mg} \mathrm{L}^{-1}$ IAA ile $0.5 \mathrm{mg} \mathrm{L}^{-1}$ $\mathrm{KIN}, 0.25 \mathrm{mg} \mathrm{L}^{-1} \mathrm{BAP}, 1.0 \mathrm{mg} \mathrm{L}^{-1}$ IBA ortamlarından elde edilen in vitro örneklerinden daha düşük DPPH aktivitesi sergilemiştir (Şekil 4).

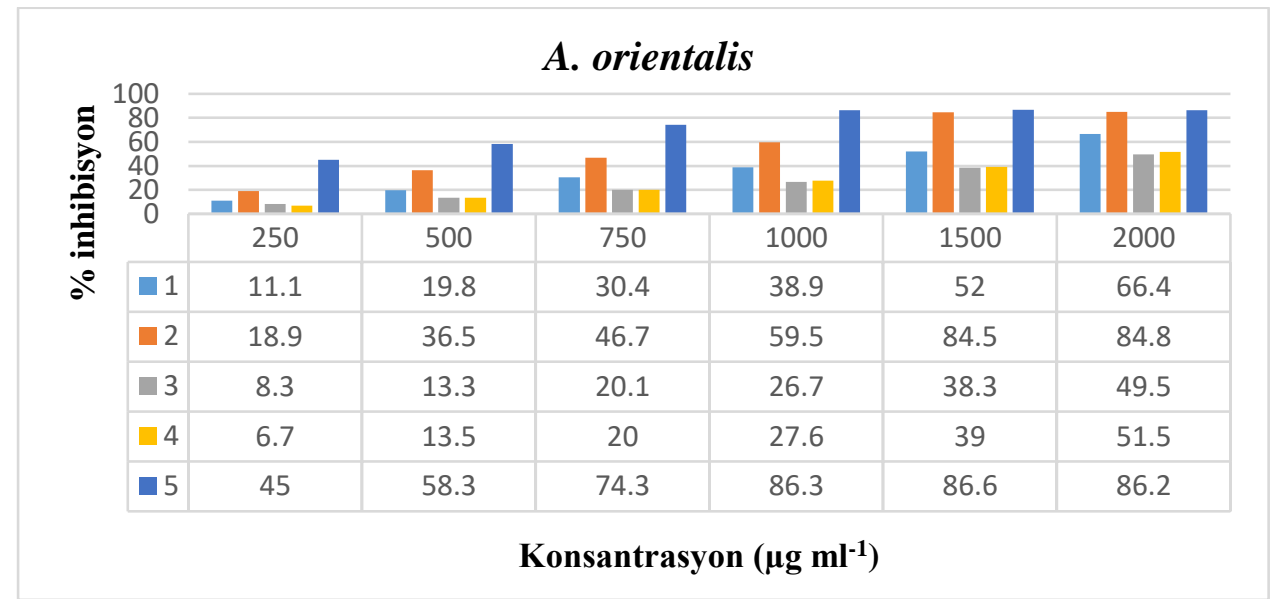

Şekil 3. A. orientalis'e ait farklı konsantrasyonlardaki ekstraktların DPPH süpürme aktivitesinin \% inhibisyon değerleri (1, 2, 3, 4, 5 numaraları Çizelge 3'deki No ifadelerin karşılığıdır)

$250 \mu \mathrm{g} \mathrm{m} \mathrm{m}^{-1}$ konsantrasyondaki en yüksek DPPH aktivitesi $A$. orientalis taksonunun kök ekstraktlarında \%45.0, ikinci sırada $A$. sieheana taksonunun herba kısımlarında \%21.1 olarak tespit edilmiştir. Her iki takson içinde en düşük antioksidan aktivitesi $2.0 \mathrm{mg} \mathrm{L}^{-1}$ IBA ortamındaki tam bitki örneklerinde kaydedilmiştir. Fakat, her iki taksonda da $0.25 \mathrm{mg} / \mathrm{L} \mathrm{BAP,} 0.5 \mathrm{mg} / \mathrm{L} \mathrm{KIN}, 1.0 \mathrm{mg} / \mathrm{L}$
IBA içeren ortamda sürgün eksplantlarından elde edilen sürgün ekstraktlarında da yüksek oranda DPPH aktivitesi gözlenmiştir (2000 $\mu \mathrm{g} \mathrm{m \textrm {ml } ^ { - 1 }}$ ekstraklarda, $A$. orientalis $\% 84.8$ ve $A$. sieheana \%79.8). in vitro uygulamaları ile Alkanna türlerinden elde edilen örneklerde yüksek antioksidan aktivite sergileyebileceği tespit edilmiştir. Önceki çalışmalarda da doku kültürü 
örneklerin in vivo örneklerden daha yüksek ve Mallick, 2017; Prihantini ve ark., 2018). antioksidan aktivite gösterdiği rapor edilmiştir (Roy

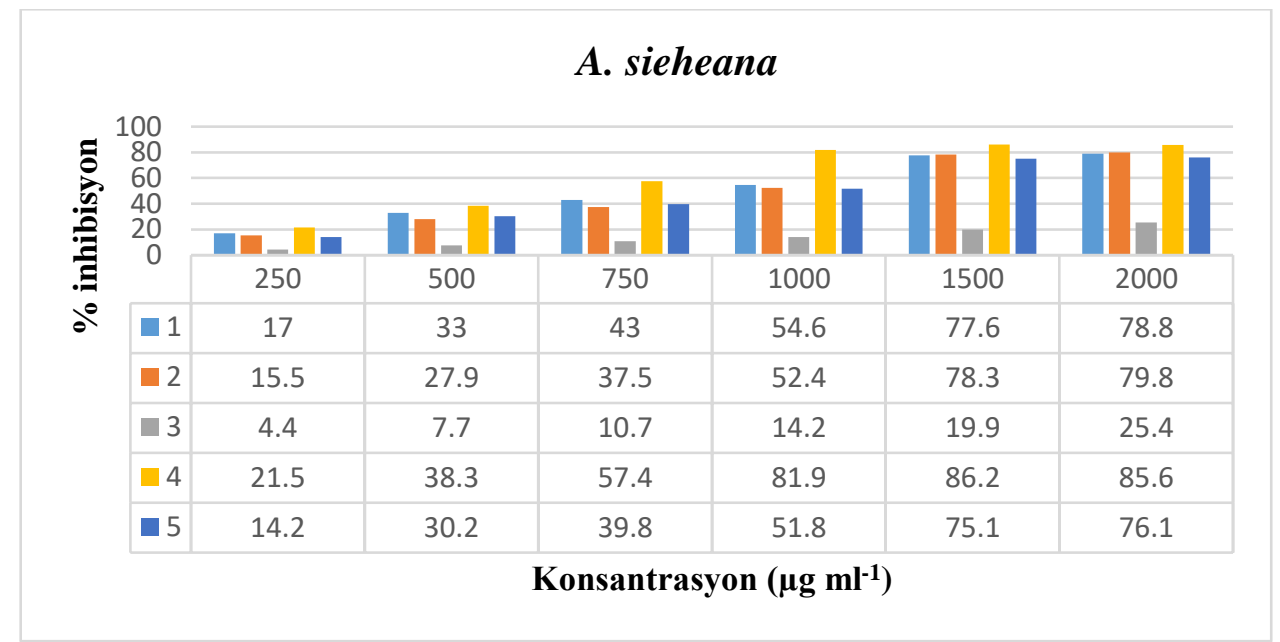

Şekil 4. A. sieheana taksonuna ait farklı konsantrasyonlardaki eksrakların DPPH süpürme aktivitesinin \% inhibisyon değerleri $(1,2,3,4,5$ numaraları Çizelge 3'deki No ifadelerin karşılığıdır)

Köklerinde $\mathrm{A} /$ Ş bulunduran diğer türlerin $\mathrm{DPPH}$ aktiviteleri incelendiğinde, $A$. tinctoria köklerinin 500 ppm konsantrasyonunda yüksek antioksidan aktivitesine sahip olduğunu bildirilmiştir (Assimopoulou ve Papageorgiou 2005). Benzer olarak, $A$. orientalis bitkisinin sulu ekstraktlarında antioksidan aktivitesi olmadığını ve metanollü ekstraktlarının $500 \mu$ l'lik konsantrasyonunda en yüksek antioksidan aktivitesi (\%98) olduğu tespit edilmiştir (Mothana ve ark., 2008). Bu çalışmada ise $A$. orientalis ve $A$. sieheana taksonlarının metanollü kök eksptraklarının $500 \quad \mu \mathrm{g} \quad \mathrm{ml}^{-}$ ${ }^{1}$ konsantrasyonlarında sırasıyla $\% 58.3$ ve $\% 30.2$ olarak bulunmuştur. Fakat $1000 \mu \mathrm{g} / \mathrm{ml}$ konsantrasyonlarında $A$. orientalis doyum noktasına ulaşarak en yüksek \%86.3 inhibisyon değerine ulaşmıştır. A. sieheana taksonu ise 2000 $\mu \mathrm{g} / \mathrm{ml}$ konsantrasyonunda $\% 76.1$ en yüksek inhibisyon değeri sergilemiştir. A. orientalis taksonunun metanollü kök ekstraklarının DPPH aktivitesinin $A$. sieheana taksonundan daha yüksek olduğu tespit edilmiştir. Özer ve ark. (2010) $A$. tinctoria türünün kuru herbal kısımlarının 0.4 ve $0.8 \mathrm{mg} \mathrm{ml}$ metanol ekstraktlarının en yüksek DPPH aktivitesine sahip olduğunu açıklamışlardır. Salimikia ve ark. (2015) Alkanna bracteosa, $A$. frigida, $A$. orientalis ve $A$. tricophila köklerinin antioksidan aktivitelerini farklı çözücüler içerisinde en iyi çözücünün butonol olduğunu, hatta pozitif kontrol olarak kullanılan kuersetin kimyasalından daha yüksek DPPH aktivitesi sergilediğini rapor etmişlerdir.

\section{Sonuç ve Öneriler}

Köklerinde $\mathrm{A} /$ Ş içeren bitki türleri birçok biyolojik aktivitelere sahip olmasından dolayı çok önemli türler arasında yer almaktadır. Bu çalışma, endemik bir tür olan $A$. sieheana türünün sekonder metobolit ve antioksidan aktivitesi üzerinde yapılan ilk çalışmadır. A. sieheana taksonunun herba örneklerinin yüksek fenolik içerik ve antioksidan aktivitesi sergilediği tespit edilmiştir. Kök ekstraktında yüksek oranda $\mathrm{A} /$ Ş olmasına rağmen düşük aktivite sergilemesi, herba kısmında antioksidan aktivitesi yüksek bileşik olabileceğini göstermektedir. Bu çalışmada elde edilen verilere göre her iki tür in vivo ve in vitro koşullarında karşılaştırıldığında $\mathrm{A} / \widehat{\text { ş }}$ üretimi bakımından $A$. sieheana türünün potansiyelinin daha yüksek olduğu, ticarileştirme çabalarında daha öne çıkabileceği düşünülmektedir. Ayrıca elde edilen veriler doğrultusunda gelecekte yapılacak çalışmalarda gıda, kozmetik ve farmakoloji gibi alanlarda kullanılabilecek doğal aktif bileşenlerin elde edilmesi için $A$. sieheana türünün toprak üstü herba kısmının, Alkanna orientalis türünde ise kök kısımları üzerinde odaklanılmasının önemli olabileceği öngörülmüştür.

\section{Kaynaklar}

Arvouet-Grand, A., Vennat, B., Pourrat, A., Legret, P. 1994. Standardisation d’un extrait de propolis et identification des principaux constituants. J. de Pharmacie de Belgique, 49: 462-468.

Assimopoulou, A.N., Papageorgiou, V.P. 2005. Radical scavenging activity of Alkanna tinctoria root extracts and their main constituents hydroxynaphthoquinones. Phytother Res., 19:141-147.

Assimopoulou, A.N., Karapanagiotis, I., Vasiliou A., Kokkini, S., Papageorgiou, V.P. 2006. 
Analysis of alkannin derivatives from Alkanna species by high-performance liquid chromatography/photodiode array/mass spectrometry. Bıomedical Chromatography, 20: 1359-1374.

Bageri, S., Sanjarian, F., Haghbeen, K., Ebrahimi, M.A. 2011. Establıshment Of Cell Suspension Culture From Onosma Dasytrıchum Seed Callus Culture. International Research Journal of Applied and Basic Sciences, 2 (10): 392-397.

Chang, M.J., Huang, G.J., Ho, Y.L., Lin, I.H., Huang, S.S., Chang, T.N., Chang, H.Y., Chang, Y.S. 2008. Study on the antioxidant activities of crude extracts from the roots of Arnebia euchroma and Lithospermum erythrorhizon, Mid-Taiwan J. Med., 13: 113121.

Chung, B.Y., Lee, Y.B., Baek, M.H., Kim, J.H., Wi, S.G., Kim J.S. 2006. Effects of low-dose gamma-irradiation on production of shikonin derivatives in callus cultures of Lithospermum erythrorhizon. S. Radiation Physics and Chemistry, 75, 1018-1023.

Davis, P.H., Mill, R.R., Tan. K. 1988. Flora of Turkey and the East Aegean Islands, 6. Edinburgh University press, Edinburgh, pp.402-434.

Düzgüneş, O., Kesici, T. ve Gürbüz, F. 1983. İstatistik Metotları 1. A.Ü. Zir.Fak. Yay. No: 862, Ankara.

Gezer, K., Duru, M.E. Kıvrak, I., Türkoğlu, A., Mercan, N., Türkoğlu, H. and Gülcan, S. 2006. Free-radical Scavenging Capacity and Antimicrobial Activity of Wild EdibleMushroom of Turkey. African journal of Biyotechnology, 5 (20):1924-1928.

Güner, A., Aslan, S., Ekim, T., Vural, M., Babaç T. 2012. Türkiye Bitkileri Listesi. NGBB and Flora Araştırmaları Derneği Yayını, İstanbul.

Gür, C., Akgün, İ.H., Deliloglu-Gurhan, İ., Korkmaz, K.S., Bedir, E. $2010 . \quad$ Cytotoxic Naphthoquinones from Alkanna cappadocica, J. Nat. Prod., 7: 860-864.

Haghbeen, K., Pourmolaei, S., Mareftjo, M.J., Mousavi, A., Akbari Noghabi, K., Hosseini Shirazi, F., Meshkat, A. 2011. Detailed Investigations on the Solid Cell Culture and Antimicrobial Activities of the Iranian Arnebia euchroma. Journal of Biomedicine and doi:10.1155/2011/165852.

Han, X., Kang, K.A., Piao, M.J., Zhen, A.X., Hyun, Y.J., Kim, H.M., Ryu, Y.S., Hyun, J.W. 2019. Shikonin Exerts Cytotoxic Effects in Human Colon Cancers by Inducing Apoptotic Cell Death via the Endoplasmic Reticulum and
Mitochondria-Mediated Pathways. Biomol Ther (Seoul), 27(1): 41-47.

Hunter, C.S., Kilby, N.J., 1990. Betanin Production and Release In Vitro from Suspension Cultures of Beta vulgaris. Methods Mol Biol., 6:545-554.

Kajimoto, S., Hori, M., Manabe, H., Masuda, Y., Shibayama-Imazu, T., Nakajo, S., Gong, X.F., Obama, T., Itabe, H. and Nakaya, K. 2008. A tyrosine kinase inhibitor, $\beta$ hydroxyisovalerylshikonin, induced apoptosis in human lung cancer DMS114 cells through reduction of dUTP nucleotidohydrolase activit. BBA-Mol Basis Dis., 1782:241-250.

Kumar, R., Sharma, N., Malik, S., Bhushan, S., Sharma, U.K., Kumari, D., Sinha, A.U., Sharma, M., Ahuja, P.S. 2011. Cell suspension culture of Arnebia euchroma (Royle) Johnston - A potential source of naphthoquinone pigments. Journal of Medicinal Plants Research, 5(25): 60486054.

Mahmoudi, S.Z., Seyedabadi, M., Esfahani, H.R.M., Amanzadeh, Y., Ostad, S.N. 2012. Antiinflammatory and analgesic activity of Alkanna bracteosa and Alkanna tricophila. Natural Product Research, 26:6, 564-569.

Mothana, R.A.A., Abdo, S.A.A., Hasson, S., Althawab, F.M.N., Alaghbari, S.A.Z., Lindequist, U. 2008. Antimicrobial, Antioxidant and Cytotoxic Activities and Phytochemical Screening of Some Yemeni Medicinal Plants. Advance Access Publication, 7(3):323-330.

Özer, M.S., Sarıkürkcü, C., Tepe, B., Can, S. 2010. Essential oil composition and antioxidant activities of alkanet (Alkanna tinctoria subsp. tinctoria). Food Science and Biotechnology, 19, 1177-1183.

Pal, M., Chaudhury, A. 2010. High Frequency Direct Plant Regeneration, Micropropagation and Shikonin Induction in Arnebia hispidissima. J. Crop Sci. Biotech., 13 (1) : 13-20.

Prihantini, A.I., Sukıto, A., Tachibana, S. 2018. Production of antioxidant compounds from tissue culture of Artemisia annua. Nusantara bioscience, 10(4): 251-255.

Roy, D., Mallick, B. 2017. Phytochemical Analysis of Field Grown and Tissue Culture Derived Mentha arvensis L. Plants with special reference to Antioxidative Potentials. International Journal of Engineering Technology Science and Research, 4(11):2394 - 3386.

Papageorgiou, V.P., Assimopoulou, A.N. and Ballis, AC. 2008. Alkannins and shikonins: a new 
class of wound healing agents. Curr Med Chem., 15:3248-3267.

Salimikia, I., Yazdinezhad, A.Z., Golfakhrabadi, F., Esfahani, H.R.M. 2015. In vitro antioxidant and free radical scavenging activity of four Alkanna species growing in Iran. Pharmacognosy Res., 7(1): 100-104.

Singleton, V.L., Orthofer, R. and Lamuela-Raventos, R.M. 1999. Analysis of total phenols and other oxidation substrates and antioxidants by means of Folin-Ciocalteu reagent. Methods Enzymol. 299, 152-178.

Şengül, M., Yıldız, H., Güngör, N., Cetin, B., Eser, Z. Ve. Ercişli, S. 2009. Total phenolic content, antioxidant and antimicrobial activities of some medicinal plants. Pak. J. Pharm. Sci., 22(1): 102-106.

Xu J., Koizumi K., Liu M., Mizuno Y., Suzaki M., litsuka H., Inujima A., Fujimoto M., Shibahara N., Shimada Y. 2019. Shikonin induces an anti-tumor effect on murine mammary cancer via p38-dependent apoptosis. Oncology Reports, 41(3): 20202026.

Tošić, S., Stojičić, D., Slavkovska, V., MihailovKrstev, T., Zlatković, B., Budimir, S., Uzelac, B., 2019. Phytochemical composition and biological activities of native and in vitropropagated Micromeria croatica (Pers.) Schott (Lamiaceae). Planta, 249:1365-1377.

Vinothini, K., Devi, M.S., Shalini, V., Sekar, S., Semwal, R.B., Arjun, P., Semwal K. 2017. In vitro micropropagation, total phenolic content and comparative antioxidant activity of different extracts of Sesbania grandiflora (L.) Pers. Current Science, 113(6):1142-1147.

Zare, K.H., Nazemiyeh, H., Movafeghi, A., Khosrowshahli, M., Motallebi-Azar, A., Dadpour, M., Omidi, Y. 2010. Bioprocess engineering of Echium italicum L.: induction of shikonin and alkannin derivatives by twoliquid-phase suspension cultures. Plant Cell Tiss Organ Cult., 100:157-164. 